Research Paper:

\title{
The Effectiveness of Integrated Model of Self-regulation- attachment Couple Therapy on Dimensions of Marital Satisfaction of Insecure Couples
}

Tooraj Sepahvand $^{1^{*}}$ (i)

1. Department of Psychology, Faculty of Humanities, Arak University, Arak, Iran

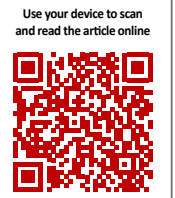

Citation Sepahvand T. The Effectiveness of Integrated Model of Self-regulation-attachment Couple Therapy on Dimensions of Marital Satisfaction of Insecure Couples. Avicenna J of Neuropsychophysiology. 2018; 5(4):159-168. http://dx.doi.org/10.32598/ ajnpp.4.3.275

doi http://dx.doi.org/10.32598/ajnpp.4.3.275

Article info:

Received: 10 Apr 2018

Accepted: 13 Aug 2018

Available Online: 01 Nov 2018

Keywords:

Couple therapy, Integration, Self regulation, Attachment, Satisfaction

\begin{abstract}
Introduction: Nowadays, marital satisfaction is not easily achieved. Therefore, helping couples have lasting and satisfying marriages is essential.

Objectives: This research examined the effectiveness of the integrated model of self-regulationattachment couple therapy on the dimensions of marital satisfaction of insecure couples.

Materials and Methods: The research was a quasi-experimental study with a pretest-posttest design and control group. The research sample was selected from the couples referring to the counseling centers of Khorramabad City, Iran. The couples that at least one of them had an insecure attachment style based on the Adult Attachment Inventory were selected using the purposive sampling method. Then the couples were randomly assigned to the experimental (11 couples) and control (11 couples) groups. Before performing the couple therapy program, the ENRICH questionnaire was administered to all couples as the pretest. Then the couples of the experimental group participated in a therapeutic program during the 8 weekly sessions, but the control group remained on the waiting list. After the completion of the therapeutic sessions, the couples of the two groups completed this questionnaire once again as the posttest. Finally, the obtained data of the two groups were analyzed by ANCOVA and MANCOVA.
\end{abstract}

Results: The results of ANCOVA indicated that self-regulation-attachment couple therapy was an effective treatment in increasing marital satisfaction. The results of MANCOVA also showed that this therapeutic program increased marital satisfaction based on the sexual relationship, marriage and children, and spiritual beliefs subscales.

Conclusion: Integrated model of self-regulation-attachment couple therapy could be an effective treatment for promoting the marital satisfaction of insecure couples.

* Corresponding Author:

Tooraj Sepahvand, PhD.

Address: Department of Psychology, Faculty of Humanities, Arak University, Arak, Iran.

Tel: +98 (916) 6972714

E-mail: t-sepahvand@araku.ac.ir 


\section{Introduction}

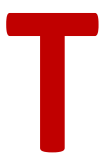

oday, exploring and understanding the different aspects of the romantic relationship is a worthy challenge for research [1]. In spite of abundant knowledge about preventing marital conflicts, understanding how to help couples have lasting and satisfying marriages, is still in the primary stages [2]. Researchers have assessed perceptions of benefits and costs of romantic relationships [3] and psychopathology involved in these relationships [4]. Almost all marriages and other couple relationships begin with high satisfaction [5]. However, marital satisfaction is not easily achieved [6]. Halford believed that, in many couples, these initial positive feelings decline over time, and couple relationship distress is a current problem [7]. Therefore, it would seem that planned interventions to improve marriages and couple relationships may have a positive effect on unhappy marriages [8]. Especially, integrative approaches to couple therapy have important implications for clinical practice about couples [9].

One of the essential approaches of couple therapy is self-regulation couple therapy. According to this perspective, the process of marital therapy usually includes moving and encouraging clients to recognize the changes that could be made to improve their relationship, until being dependent on changes in their partners [10]. Many findings explicitly show that couple intervention that enhances self-regulation relationship improves a couple's satisfaction [11], and decrease emotional abuse and marital distress [12]. However, in recent years, researchers of self-regulation couple therapy state that some couples need more extensive therapy to attain self-change goals of their relationship, and using the techniques of other approaches can help the couples to change their relationships [13].

The attachment theory has advantages [14], and its application can especially enhance self-regulation in behavioral couple therapy $[10,13]$. The critical point is that attachment theory is essentially a self-regulation theory [15], and attachment models have applications in the development of self-regulation capacities [16, 17]. Therefore, theoretical models that focus on selfregulation and mutual regulation suggest that individuals who have experienced trauma in their relationship tend to use insecure, avoidant, disorganized, or ambivalent strategies of stress regulation. These strategies create problematic interactive patterns in their couple relationships [18].
Thus, when there is an attachment breach, couples are taught how the state of interactive dysregulation can weaken and undermine their attachment bond if they do not attempt to stop it by more reparative approaches. Furthermore, each partner is encouraged to learn how to do self-regulation and become more sensitive to the partners' affection regulation. This treatment builds mutual awareness and empathy within the dyadic relationship and interrupts the ongoing negative cycle [19]. Therefore, researchers propose the theory of attachment as an organizing framework or meta-perspective for couples' therapy and marital intervention [20]. Byng-Hall believed that the internal working model might affect the cognitive-emotive process by which each partner implicitly regulate goals or ideals for relationship or criteria for satisfaction of couple relationship [20]. So if the behavioral interventions consider the potential motivations behind the behaviors, such as people's preferred ways for controlling the attachment anxiety, relationship goals of couples, and emotional experiences, then acquired skills may be used better and therapists more effective in moving their couples toward behavior change [21].

With such a perspective, the researchers investigated the interactive effect of attachment anxiety and relationship threat on self-regulation by integrating research on attachment anxiety, rejection, self-regulation, and health behaviors in an exploratory examination. The results of this study indicated that the women (not men) develop excessive attachment anxiety, experience self-regulation failure when relationship threat is elicited [22]. Another research also shows the efficacy of the integrated model of self-regulationattachment couple therapy on marital satisfaction and wellbeing of couples [23].

In general, secure clients appear to be better at making use of treatment than insecure clients [24], and essentially secure attachment style facilitates the ability of people to learn new experiences and, if necessary, accept change in themselves and others [14]. Understanding the different attachment styles of couples may provide essential clues and guidelines to establish a secure base of operation for the negotiation of change [20]. Thus, all therapists have to relate, in their particular ways, to attachments when they engage with family problems [25]. Also, they can use their chosen techniques when a secure base in therapy is established and enrich and facilitate their current practice $[20,21]$. Thus, this research aimed to examine the efficacy of the integrated model of self-regulation-attachment couple 
therapy on dimensions of marital satisfaction of insecure couples.

\section{Materials and Methods}

This research was a quasi-experimental study with a pretest-posttest design and control group. The statistical population comprised the couples referring to the counseling centers of Khorramabad City, who attempted to receive professional aids because of communicational and marital problems. The research sample was selected by purposive sampling method among the couples that at least one of them had an insecure attachment style, based on the Adult Attachment Inventory. Given that these couples are few in these counseling centers, a sample with the least number but enough for experimental research were selected, and 11 couples $(n=22)$ were randomly assigned to the experimental group and 11 couples $(n=22)$ to the control group.

The criteria for choosing the couples were as follows: being married for at least 1 year and at most 15 years, lacking serious problems such as severe physical or mental illnesses and substance abuse, not willing to divorce, and having a desire to participate in the study program. An expert psychologist assessed these criteria. Before performing the couple therapy program, the ENRICH questionnaire was administered to all couples as the pretest. Then, the couples of the experimental group participated in a couple therapy program for 8 weekly sessions, but the control group remained on the waiting list. After the completion of the therapeutic sessions, the couples of the two groups completed the questionnaires again as the posttest. For decreasing the conflicting factors in the process of therapy, the agreement of the couples was obtained, and the problematic conflicts were resolved during the therapeutic sessions. Finally, the collected data of the two groups were analyzed by multivariate analysis of variance (MANOVA).

\section{Adult Attachment Inventory (AAI)}

The Adult Attachment Inventory (AAI) is a questionnaire derived from the attachment style questionnaire [26], the relationship questionnaire [27], and the attachment history questionnaire [28] and validated to measure attachment styles in the Iranian population $[29,30]$. The AAl is a 15 -item questionnaire with three subscales of secure attachment style, avoidant attachment style, and ambivalent attachment style, each of which has 5 items. Each item is rated on a 5-point Likerttype scale ranging from 1 (very little) to 5 (very much).
The Cronbach coefficient alpha values for the subscales of secure, avoidant, and ambivalent styles were calculated in a sample of 1480 participants (860 females, 620 males). The Cronbach alpha values were $0.85,0.84$, and 0.85 for secure, avoidant, and ambivalent attachment styles, respectively, for all participants. The test-retest reliability of the AAI was calculated twice in a sample of 300 participants at a 4-week interval. The coefficients of secure, avoidant, and ambivalent attachment styles for all participants were $0.87,0.83$, and 0.84 , respectively. All correlation coefficients were significant at $\mathrm{P}<0.001$. These scores indicate adequate test-retest reliability of the AAI. Factor analysis identified that secure, avoidant, and ambivalent attachment styles were confirmed by the AAI [29]. In another study, the internal reliability coefficients were $0.90,0.87$, and 0.85 for secure, avoidant, and ambivalent attachment styles, respectively [30]. The Cronbach's alpha value of this questionnaire in this research was calculated as 0.79 .

Enriching and Nurturing Relationship Issues, Communication, and Happiness

Enriching and nurturing relationship issues, communication, and happiness or simply ENRICH marital satisfaction questionnaire is a 115 -item instrument, and another form of it has 125 items. This questionnaire consists of 12 subscales [31]. ENRICH questionnaire has good psychometric characteristics. Its internal consistency is estimated from 0.73 to 0.90 [32]. All subscales of this questionnaire distinguish satisfied from unsatisfied couples, indicating the high criterion validity of this questionnaire [31]. Fowers and Olson [33] found that ENRICH can differentiate between happy and unhappy married couples with $85 \%$ to $90 \%$ accuracy. In this research, the Iranian 47-item ENRICH was used, and its internal consistency was reported to be about 0.95 [34]. Nine subscales of this version of ENRICH are personality issues, marital communication, conflict resolution, financial management, leisure activities, sexual relationship, marriage and children, family and friends, and spiritual beliefs. In this research, the Cronbach alpha of this questionnaire was found 0.87 .

Integrated Model of Self-Regulation-Attachment Couple Therapy

According to theories about self-regulation $[10,13]$ and attachment [14, 20, 25], the integrated model of self-regulation-attachment couple therapy is the change of behaviors, cognitions, and emotions of couples by themselves that facilitates reconstruction and expansion of attachment styles by helping the therapist 
Table 1. Titles and contents of sessions in the integrated model of self-regulation-attachment couple therapy

\begin{tabular}{|c|c|c|}
\hline Session & Title & Content \\
\hline 1 & Primary assessment & $\begin{array}{l}\text { Introduction, explaining the sessions structure, investigating the treatment motivation, } \\
\text { examining the common expressions of couples about the problem, individual interview, } \\
\text { obtaining the information that is not possible in the presence of a spouse, performing the } \\
\text { pretest, assessing the level of distress, attachment styles, essential areas of conflict, and } \\
\text { areas of change, describing the approach of couple therapy, negotiating about the tasks } \\
\text { must be done before each sessions. }\end{array}$ \\
\hline 2 & $\begin{array}{l}\text { Continuance of assess- } \\
\text { ment and negotiation }\end{array}$ & $\begin{array}{l}\text { Reviewing the previous sessions, individual interview, obtaining more information that is } \\
\text { not possible in the presence of a spouse, creating the shared understanding of the relation- } \\
\text { ship, the therapeutic agreement, and observational evaluation of couples interaction. }\end{array}$ \\
\hline 3 & $\begin{array}{l}\text { Continuance of assess- } \\
\text { ment, recognition of } \\
\text { negative interactional } \\
\text { cycle and behaviors } \\
\text { related to attachment }\end{array}$ & $\begin{array}{c}\text { Evaluating the problems and obstacles of attachment, understanding and identifying } \\
\text { negative interactional cycles, investigating the role of behavioral performance of couples } \\
\text { in maintaining or aggravating the insecurity and dissatisfaction, investigating the role of } \\
\text { caregiver and who is seeking the caregiving, explaining the change and flexibility of attach- } \\
\text { ment styles. }\end{array}$ \\
\hline 4 & $\begin{array}{l}\text { Analysis and change of } \\
\text { the emotions }\end{array}$ & $\begin{array}{l}\text { Opening the critical experiences that are related to attachment, acceptance of unverified } \\
\text { fundamental emotions, acceptance of interactional cycle by couples. }\end{array}$ \\
\hline 5 & Emotional engagement & $\begin{array}{l}\text { Increasing the identification of attachment needs, expressing and accepting the emotions, } \\
\text { promoting the new ways of interaction, focusing on self, not on others, expressing the } \\
\text { demands and wishes in the presence of the spouse }\end{array}$ \\
\hline 6 & $\begin{array}{l}\text { Feedback and nego- } \\
\text { tiation about goals and } \\
\text { evaluate the possibil- } \\
\text { ity of short-time self- } \\
\text { change }\end{array}$ & $\begin{array}{l}\text { Identifying the communication strengths, communication weaknesses, behaviors that make } \\
\text { unsafe communications, initiating and persisting factors of relationship problems, present- } \\
\text { ing the participatory and practical model of the therapist about the communication that } \\
\text { is based on the above points, determining the possible goals and evaluating the high-level } \\
\text { self-regulating skills of couples. }\end{array}$ \\
\hline 7 & $\begin{array}{l}\text { Performing the short- } \\
\text { term self-change and } \\
\quad \text { supporting it }\end{array}$ & $\begin{array}{l}\text { Discussing about fulfilling the goals of self-change in couples, helping them to assess the } \\
\text { impact of self-change on their relationship, analyzing couples' interactions between ses- } \\
\text { sions and paying attention to the self-change goals specified in previous sessions, enhancing } \\
\text { and stimulating self-change, ensuring of linking the proposed specific changes of couples to } \\
\text { their communicational goals, helping the couples to further development of needed goals } \\
\text { of change. }\end{array}$ \\
\hline 8 & $\begin{array}{l}\text { Continuance of self- } \\
\text { change, summation, } \\
\text { and ending }\end{array}$ & $\begin{array}{l}\text { Helping the spouses to do self-regulation in their behavioral, thinking, and feeling ways to } \\
\text { each other, natural targeting at home and applying the obtained results outside the treat- } \\
\text { ment sessions, reaching the conclusion that there is no need for a therapist to be present, } \\
\text { and change of self is more important than change of spouse, performing the posttest. }\end{array}$ \\
\hline
\end{tabular}

AJNPP

and creating a secure interactional atmosphere among them. This therapeutic model has been made by the integration of theoretical concepts and therapeutic principles of self-regulation and attachment theories performed during 8 sessions. Table 1 presents The titles and content of sessions in this therapeutic program.

\section{Results}

The collected data from the experimental group (11 couples, Mean $\pm S D$ age, 31.2 [5.4] years), and the control group (11 couples, Mean \pm SD age, 34 [5.8] years) were analyzed. These couples had 0 to 2 children, and their age differences were between 2 and 12 years. Table 2 presents the pretest and posttest scores of the participants in marital satisfaction and its subscales.

Since the present research had a pretest-posttest quasi-experimental design with a control group, the data were analyzed by the analysis of covariance (ANCOVA) and multivariate analysis of covariance (MANOVA). The pre-assumptions of these analyses were examined. The tests of homogeneity for regression line for two experimental conditions were not significant in all variables $(P<$ 0.01 ), the covariance matrices of two groups were equal and had no significant differences (Box's $M=53.818$, $\mathrm{P}=0.672$ ) and Bartlett's test of sphericity showed significant differences between dependent variables (Approx. Chi-Square $=73.768, \mathrm{P}=0.004$ ), that included subscales of marital satisfaction. With confirming these pre-assumptions, ANCOVA and MANCOVA were performed. Table 3 presents the results of ANCOVA for comparisons between the experimental and control groups in marital satisfaction.

The results of ANCOVA indicate the pretest effect for two groups. Nevertheless, after controlling the pretest effect, it was found that the effect of integrated selfregulation-attachment couple therapy on the posttest scores of the two groups was significant, and the two 
Table 2. The results of pretest and posttest scores of experimental and control groups in marital satisfaction and its subscales

\begin{tabular}{|c|c|c|c|c|c|}
\hline \multirow{2}{*}{ Variables } & \multirow{2}{*}{ Group } & \multicolumn{4}{|c|}{ Mean $\pm S D$} \\
\hline & & Pre-test & Post-test & Pre-test & Post-test \\
\hline \multirow{2}{*}{$\begin{array}{c}\text { Marital } \\
\text { satisfaction }\end{array}$} & Experimental & 144.54 & 159.36 & 22.91 & 19.76 \\
\hline & Control & 152.45 & 154.41 & 34.79 & 32.77 \\
\hline \multirow{2}{*}{$\begin{array}{l}\text { Personality } \\
\text { issues }\end{array}$} & Experimental & 13.45 & 15.86 & 4.39 & 4.24 \\
\hline & Control & 14.09 & 15.86 & 5.27 & 5.45 \\
\hline \multirow{2}{*}{$\begin{array}{c}\text { Marital } \\
\text { communication }\end{array}$} & Experimental & 14.63 & 16.50 & 3.94 & 3.63 \\
\hline & Control & 15.18 & 15.54 & 5.85 & 5.39 \\
\hline \multirow{2}{*}{$\begin{array}{l}\text { Conflict } \\
\text { resolution }\end{array}$} & Experimental & 13.13 & 15.09 & 3.77 & 3.62 \\
\hline & Control & 14.27 & 15.22 & 5.44 & 4.70 \\
\hline \multirow{2}{*}{$\begin{array}{c}\text { Financial } \\
\text { management }\end{array}$} & Experimental & 15.22 & 15.50 & 3.89 & 3.41 \\
\hline & Control & 15.95 & 16.54 & 4.54 & 3.62 \\
\hline \multirow{2}{*}{$\begin{array}{l}\text { Leisure } \\
\text { activities }\end{array}$} & Experimental & 16.40 & 16.95 & 3.38 & 3.21 \\
\hline & Control & 16.00 & 16.27 & 3.30 & 3.39 \\
\hline \multirow{2}{*}{$\begin{array}{c}\text { Sexual } \\
\text { relationship }\end{array}$} & Experimental & 17.45 & 19.63 & 2.53 & 2.62 \\
\hline & Control & 17.68 & 16.95 & 3.93 & 3.55 \\
\hline \multirow{2}{*}{$\begin{array}{l}\text { Marriage } \\
\text { and children }\end{array}$} & Experimental & 15.04 & 17.00 & 2.39 & 2.84 \\
\hline & Control & 17.27 & 16.50 & 3.22 & 3.40 \\
\hline \multirow{2}{*}{$\begin{array}{l}\text { Family } \\
\text { and friends }\end{array}$} & Experimental & 15.45 & 16.22 & 3.29 & 3.17 \\
\hline & Control & 17.00 & 16.45 & 3.11 & 4.16 \\
\hline \multirow{2}{*}{$\begin{array}{l}\text { Spiritual } \\
\text { beliefs }\end{array}$} & Experimental & 17.77 & 19.59 & 2.63 & 2.66 \\
\hline & Control & 18.50 & 18.18 & 4.92 & 4.58 \\
\hline
\end{tabular}

AJNPP

groups were different in the posttest. Accordingly, the hypothesis, asserting that the integrated model of selfregulation-attachment couple therapy increases marital satisfaction was confirmed $\left(F_{1,41}=10.55, P=0.002\right)$, which indicates the effect of the mentioned program on marital satisfaction.

This research also examined the effect of the therapeutic program on the subscales of marital satisfaction with the ENRICH questionnaire. Accordingly, MANOVA was used to analyze the differences between the two groups in these variables. Table 4 presents the results of MANCOVA for subscales of marital satisfaction.
Based on Table 4, the effect of group membership (therapeutic program) on a linear compound of dependent variables (subscales of marital satisfaction) was significant after the control of the pretest effect. Accordingly, Table 5 presents the results of univariate analysis for examination of the inter-group effects of these subscales.

The results of Table 5 indicate that the observed $F$ scores for the subscales of sexual relationship, marriage and children, and spiritual beliefs were significant. Therefore, the means of these variables in the two groups had significant differences, but there were no such differences for other variables. Finally, Table 6 
Table 3: Results of ANCOVA analysis for comparison between the experimental and control groups in marital satisfaction

\begin{tabular}{ccccccc}
\hline Variable & Score & Sum of square & df & Mean Square & F & Sig. \\
\hline $\begin{array}{c}\text { Marital } \\
\text { satisfaction }\end{array}$ & Pre-test & 25181.54 & 1 & 25181.54 & 185.20 & 0.000 \\
& Group & 1435.05 & 1 & 1435.05 & 10.50 & 0.002 \\
& Error & 5574.86 & 41 & 135.97 & & \\
& Total & 1114013 & 44 & & & \\
\hline
\end{tabular}

AJNPP

Table 4. Results of MANCOVA for subscales of marital satisfaction

\begin{tabular}{|c|c|c|c|c|c|c|}
\hline Effect & & Value & $\mathbf{F}$ & df1 & df2 & Sig. \\
\hline Pretest of personality issues & Pillai's trace & 0.415 & 1.968 & 9 & 25 & 0.088 \\
\hline Pretest of marital communication & Pillai's trace & 0.247 & 0.912 & 9 & 25 & 0.530 \\
\hline Pretest of conflict resolution & Pillai's trace & 0.247 & 0.912 & 9 & 25 & 0.531 \\
\hline Pretest of financial management & Pillai's trace & 0.632 & 4.780 & 9 & 25 & 0.001 \\
\hline Pretest of leisure activities & Pillai's trace & 0.412 & 1.944 & 9 & 25 & 0.092 \\
\hline Pretest of sexual relationship & Pillai's trace & 0.615 & 4.444 & 9 & 25 & 0.001 \\
\hline Pretest of marriage and children & Pillai's trace & 0.464 & 2.407 & 9 & 25 & 0.040 \\
\hline Pretest of family and friends & Pillai's trace & 0.500 & 2.779 & 9 & 25 & 0.021 \\
\hline Pretest of spiritual beliefs & Pillai's trace & 0.468 & 2.446 & 9 & 25 & 0.037 \\
\hline Group & Pillai's trace & 0.565 & 3.614 & 9 & 25 & 0.005 \\
\hline
\end{tabular}

AJNPP

Table 5. Univariate analysis of inter-group effects for subscales of marital satisfaction

\begin{tabular}{|c|c|c|c|c|c|c|c|}
\hline Score & $\begin{array}{l}\text { Dependent } \\
\text { Variable }\end{array}$ & $\begin{array}{l}\text { Type III Sum of } \\
\text { Squares }\end{array}$ & df & $\begin{array}{l}\text { Mean } \\
\text { Square }\end{array}$ & $\mathbf{F}$ & Sig. & $\begin{array}{c}\text { Partial eta } \\
\text { Squared }\end{array}$ \\
\hline \multirow{9}{*}{ Group } & Personality issues & 6.838 & 1 & 6.838 & 0.888 & 0.353 & 0.026 \\
\hline & Marital communication & 7.925 & 1 & 7.925 & 1.047 & 0.307 & 0.032 \\
\hline & Conflict resolution & 0.000 & 1 & 0.000 & 0.000 & 0.997 & 0.000 \\
\hline & Financial management & 6.108 & 1 & 6.108 & 1.364 & 0.251 & 0.040 \\
\hline & Leisure activities & 4.583 & 1 & 4.583 & 0.638 & 0.430 & 0.019 \\
\hline & Sexual relationship & 94.109 & 1 & 94.109 & 23.632 & 0.001 & 0.414 \\
\hline & Marriage and children & 26.830 & 1 & 26.830 & 3.373 & 0.045 & 0.139 \\
\hline & Family and friends & 0.356 & 1 & 0.356 & 0.052 & 0.821 & 0.002 \\
\hline & Spiritual beliefs & 37.343 & 1 & 37.343 & 5.581 & 0.024 & 0.145 \\
\hline
\end{tabular}


Table 6. Results of pairwise comparisons between subscales of sexual relationship, marriage and children, and spiritual beliefs

\begin{tabular}{cccccc}
\hline Dependent Variables & (I) Group & (J) Group & Mean Difference (I-J) & Std. Error & Sig. \\
\hline Sexual relationship & E & C & 3.275 & 0.674 & 0.000 \\
Marriage and children & E & C & 2.449 & 0.952 & 0.015 \\
Spiritual beliefs & E & C & 2.063 & 0.873 & 0.024 \\
\hline
\end{tabular}

presents the results of pairwise comparisons between these subscales.

The results of Table 6 also indicate the significant differences between the experimental and the control groups in these variables. Accordingly, the integrated model of self-regulation-attachment couple therapy is efficient in increasing marital satisfaction based on the subscales of sexual relationship, marriage and children, and spiritual beliefs.

\section{Discussion}

The results indicate that the integrated model of self-regulation-attachment couple therapy is useful for marital satisfaction. All couple therapies are necessary to facilitate changes in the couple relationship toward higher effectiveness of the relationship and satisfaction of the partners [20]. The findings of this research are consistent with this goal and with the research that supports the effectiveness of self-regulation couple therapy on couple relationship satisfaction [11]. These findings also confirm the results based on the approaches that consider the process of attachment in couple therapy [14], and the results of the studies that examine the treatment of couple problems and distresses based on emotionally focused therapy.

The same results have been obtained in the interventions investigated the application of emotional regulation and integration of attachment and self-regulation $[22,23]$. These results are expected considering Daniel's notion [24] about the better function of secure clients in making use of treatment, and that secure style (and expansion of secure attachment) facilitate people's ability to accept change in themselves and others [14]. On the other hand, the results of this research support the other studies that an integrated model of self-regulation-attachment couple therapy is effective in increasing marital satisfaction.

To explain how the integrated model of self-regulation-attachment couple therapy is effective on marital status, it is said that the strong relationship between marital distress and problems is related to the health and well-being of couples [7], and marital satisfaction and well-being of couples mutually affect each other [1]. So the effect of integrated couple therapy on one of them can affect the other one.

This therapeutic program was also effective on the subscales of marital satisfaction, including sexual relationship, marriage and children, and spiritual beliefs. Some research studies have shown the effectiveness of integrated couple therapy on sexually unsatisfied couples. In the present research, the sexual relationship was considered as an important problem in the couple's relationship in some therapeutic sessions, and the expansion of secure attachment and self-regulation of negative cognitions, affect the behaviors related to the sexual relationship with useful results.

About the effectiveness of this program on the subscale of marriage and children, it can be said that the filled security and self-change that integrated couple therapy can produce in couples are efficient to some extent, which easily expands to the domains of marriage and children. Finally, about the effectiveness of this program on the subscale of spiritual beliefs, it can also be said that, in spite of lack of an evident program for considering spiritual beliefs, many couples during the sessions of assessment and self-change, consider their spiritual problems and conflicts as self-change goals. Thus, the effects of this program were evident on these subscales of marital satisfaction.

The main limitation of this research was the difficulty in accessing more couples for perfect matching of the groups and better control over the intervening variables. Although the primary problems of the couples were measured in the pretest and the effect of the pretest was controlled, more confident causal results would be attained if it were possible to recruit more couples and randomly select or match them. Accordingly, future research studies should take this into account. Considering the effective use of this therapeutic 
program based on the principles of two important theories of couple therapy (attachment and self-regulation) and its positive effects on marital satisfaction, we suggest that its application can be useful and effective in decreasing problems of couples, especially those who have unhappy relationships.

\section{Conclusion}

The integrated model of self-regulation-attachment couple therapy could be an effective treatment for promoting marital satisfaction and its components in couples with insecure attachment. However, more research with different samples of couples must be done to confirm this effectiveness further.

\section{Ethical Considerations}

\section{Compliance with ethical guidelines}

This research had not received a moral code by an Ethics Committee. However, all ethical principles were considered in this article. The participants were informed about the purpose of the research and its therapeutic stages. They were also assured about the confidentiality of their information. Furthermore, they were allowed to leave the study whenever they wanted.

\section{Funding}

This research did not receive any specific grant from funding agencies.

\section{Conflict of interest}

The authors declared no conflict of interest.

\section{Acknowledgments}

The author would like to thank the couples that participated in this research.

\section{References}

[1] Zimmer-Gembeck MJ, Ducut W. Positive and negative romantic relationship quality: Age, familiarity, attachment and well-being as correlates of couple agreement and projection. Journal of Adolescence. 2010; 33:879-90. [DOI:10.1016/j.adolescence.2010.07.008] [PMID]

[2] Sayers SL, Kohn CS. Prevention of marital dysfunction: Behavioral approaches and beyond. Clinical Psychology Review. 1998; 18(6) 713-44. [DOI:10.1016/S0272-7358(98)00026-9]
[3] Kashdan TB, Blalock DV, Young KC, Machell KA, Monfort SS, McKnight $P E$, et al. Personality strengths in romantic relationships: Measuring perceptions of benefits and costs and their impact on personal and relational well-being. Psychological Assessment. 2018; 30(2):241-58. [DOI:10.1037/pas0000464] [PMID]

[4] Davila J, Capaldi DM, La Greca A. Adolescent/young adult romantic relationships and psychopathology. In: Cicchetti D. editor, Developmental Psychopathology. $3^{\text {rd }}$ ed. New York, NY: Wiley; 2016. [DOI:10.1002/9781119125556.devpsy114]

[5] Lavner JA, Bradbury TN. Patterns of change in marital satisfaction over the newlywed years. Journal of Marriage and the Family. 2010; 72(5):1171-87. [DOI:10.1111/j.1741-3737.2010.00757.x] [PMID] [PMCID]

[6] Rosen-Grandon JR, Myers JE, Hattie JA. The relationship between marital characteristics, marital interaction processes, and marital satisfaction. Journal of Counseling \& Development. 2004; 82(1):58 68. [DOI:10.1002/j.1556-6678.2004.tb00286.x]

[7] Halford WK, Snyder Dk. Universal processes and common factors in couple therapy and relationship education. Behavior Therapy. 2012; 43(1):1-12. [DOI:10.1016/j.beth.2011.01.007] [PMID]

[8] Kamp Dush CM, Taylor MG, Kroeger RA. Marital happiness and psychological well-being across the life course. Family Relations. 2008; 57(2):211-26. [DOI:10.1111/j.1741-3729.2008.00495.x] [PMID] [PMCID]

[9] Wymbs BT, Molina SGM. Integrating couple group treatment for emerging adult with ADHD symptoms. Cognitive and Behavioral Practice. 2015; 22(2):161-71. [DOI:10.1016/j.cbpra.2014.06.008]

[10] Halford WK, Sanders MR, Behrens B. Self-regulation in behavioral couple therapy. Behavior Therapy. 1994; 25(3):431-52. [DOI:10.1016/S0005-7894(05)80156-X]

[11] Halford WK, Moore EM, Wilson KL, Dyre C, Farurrgia C. Benefits of flexible delivery relationship education: An evaluation of the couple CARE program. Family Relations. 2004; 53(5):469-76. [DOI:10.1111/ j.0197-6664.2004.00055.x]

[12] Kargar M, Kimiaei SA, Mashhadi A. [The effectiveness of group couple therapy based on self-regulated on emotional abuse and marital distress (Persian)]. Journal of Family Counseling and Psychotherapy. 2014; 4(2):269-97.

[13] Halford WK. Brief therapy for couples: Helping partners help themselves. [Tabrizi M, Kardani M, Jafari F. Persian trans]. Tehran: Fararavan; 2001

[14] Johnson SM, Whiffen VE. Attachment processes in couple and family therapy. [Bahrami F, et al. Persian trans]. Tehran: Danjeh; 2002.

[15] Padykula NL, Conklin P. The self-regulation model of attachment trauma and addiction. Clinical Social Work Journal. 2010; 38:351-60. [DOI:10.1007/s10615-009-0204-6]

[16] Ablow JC, Marks AK, Feldman SS, Huffman LC. Associations between first-time expectant women's representations of attachment and their physiological reactivity to infant cry. Child Development. 2013; 84:1373-91.

[17] Asbrand J, Svaldi J, Krämer M, Breuninger C, Tuschen-Caffier B Familial accumulation of social anxiety symptoms and maladaptive emotion regulation. PLOS One. 2016; 11(4):1-14. [DOI:10.1371/ journal.pone.0153153] [PMID] [PMCID] 
[18] Feld B. Holding and facilitating interactive regulation in couples with trauma histories. Psychoanalytic Inquiry. 2004; 24(3):420-37. [DOI:10.1080/07351692409349092]

[19] Goldstein S, Thau S. Integrating attachment theory and neuroscience in couple therapy. International Journal of Applied Psychoanalytic Studies. 2004; 1(3):214-23. [DOI:10.1002/aps.73]

[20] Lindegger G, Barry T. Attachment as an integrating concept in couple and family therapy: Some considerations with special reference to South Africa. Contemporary Family Therapy. 1999; 21(2):267-88. [DOI:10.1023/A:1021655727913]

[21] Gordon KC, Christman JA. Integrating social information processing and attachment style research with cognitive-behavioral couple therapy. Journal of Contemporary Psychotherapy. 2008; 38(3):129 38. [DOI:10.1007/s10879-008-9084-2]

[22] Marques SRF. Relationship threat and self-regulation: The moderating effect of attachment anxiety. Unpublished doctoral dissertation, Queen's University; 2010.

[23] Sepahvand T, Rasoolzade Tabatabaei SK, Besharat MA, Allahyari AA. [The efficacy of integrated model of self regulation-attachment couple therapy on marital satisfaction and psychological wellbeing of couples (Persian)]. Journal of Clinical Psychology. 2015; 7(1):2739.

[24] Daniel SIF. Adult attachment patterns and individual psychotherapy: A review. Clinical Psychology Review. 2006; 26(8):968-84. [DOI:10.1016/j.cpr.2006.02.001] [PMID]

[25] Byng-Hall J. Attachment as a base for family and couple therapy. Child Psychology and Psychiatry Review. 2001; 6(1):31-6. [DOI:10.1017/S1360641700002471]

[26] Hazan C, Shaver PR. Romantic love conceptualized as an attachment process. Journal of Personality and Social Psychology. 1987; 52(3):511-24. [DOI:10.1037/0022-3514.52.3.511] [PMID]

[27] Besharat MA. [Development and validation of the Adult Attachment Inventory. (Persian)] [PhD dissertation]. Tehran: University of Tehran; 2005.

[28] Besharat MA. Development and validation of Adult Attachment Inventory. Procedia Social and Behavioral Sciences. 2011; 30:47579. [DOI:10.1016/j.sbspro.2011.10.093]

[29] Sanai B. [Scales of family and marriage measurement (Persian)]. Tehran: Besat; 2000.

[30] Olson DH, Olson AK. Empowering couples: Prepare/Enrich program. Marriage and Family: A Christian Journal. 2000; 3(1):69-81.

[31] Fowers J, Olson DH. Enrich marital inventory: A discriminant validity and cross-validation assessment. Journal of Marital and Family Therapy. 1989; 15(1):65-79. [DOI:10.1111/j.1752-0606.1989. tb00777.x] [PMID]

[32] Soleimanian AA. [Effect of irrational beliefs on marital dissatisfaction in married students. Unpublished dissertation in psychology (Persian)]. Tehran: Tarbiat Moallem University; 1994.

[33] Naaman S, Pappas JD, Makinen J, Zuccarini D, Johnson-Douglas S. Treating attachment injured couples with emotionally focused therapy: A case study approach. Psychiatry: Interpersonal and Biological Processes. 2005; 68(1):55-77. [DOI:10.1521/psyc.68.1.55.64183] [PMID]

[34] Atkins DC, Berns SB, George W, Doss B, Gattis K, Christensen A Prediction of response to treatment in a randomized clinical trial of marital therapy. Journal of Consulting and Clinical Psychology. 2005; 73(5):893-903. [DOI:10.1037/0022-006X.73.5.893] [PMID] 
